\title{
Histone deacetylase inhibitors: Apoptotic effects and clinical implications (Review)
}

\author{
SONIA EMANUELE, MARIANNA LAURICELLA and GIOVANNI TESORIERE \\ Dipartimento di Scienze Biochimiche, Università di Palermo, Policlinico, Palermo, Italy
}

Received May 22, 2008; Accepted July 17, 2008

DOI: 10.3892/ijo_00000049

\begin{abstract}
It has been shown that epigenetic modifications play an important role in tumorigenesis. Thus, affecting epigenetic tumorigenic alterations can represent a promising strategy for anticancer targeted therapy. Among the key chromatin modifying enzymes which influence gene expression, histone acetyltransferases (HATs) and histone deacetylases (HDACs) have recently attracted interest because of their impact on tumor development and progression. Increased expression of HDACs and disrupted activities of HATs have been found in several tumor types, with a consequent hypoacetylated state of chromatin that can be strictly correlated with low expression of either tumor suppressor or pro-apoptotic genes. Histone deacetylase inhibitors (HDACIs) represent a new and promising class of antitumor drugs that influence gene expression by enhancing acetylation of histones in specific chromatin domains. HDACIs have been shown to exert potent anticancer activities inducing cell cycle arrest and apoptosis. Notably, a high efficacy of these drugs has been selectively revealed in malignant cells rather than in normal cells. Moreover, the therapeutic potential of these agents is also supported by the evidence that HDACIs downregulate genes involved in tumor progression, invasion and angiogenesis. Several HDACIs are currently under clinical investigation, including vorinostat (SAHA), romidepsin (depsipeptide, FK-228), LAQ824/LBH589 and belinostat (PXD101), compounds that have shown therapeutic potential in many types of malignancies including solid tumors. Based on the ability of HDACIs to regulate many signaling pathways, co-treatment of these compounds with molecular targeted drugs is a promising strategy against many types of tumors.
\end{abstract}

Correspondence to: Dr Sonia Emanuele, Dipartimento di Scienze Biochimiche, Università di Palermo, Policlinico, Via del Vespro 129, I-90127 Palermo, Italy

E-mail: s.emanuele@unipa.it

Key words: epigenetics, histone deacetylase inhibitors, acetylation, apoptosis, tumor cells

\section{Contents}

1. Introduction

2. The regulation of gene expression by histone modifications: HATs and HDACs

3. HDAC inhibitors: Potent and selective anticancer drugs

4. Molecular aspects of HDACI pleiotropic antitumor action

5. Clinical investigations and therapeutic impact

6. Future directions/conclusions

\section{Introduction}

Epigenetic modifications consist of the reversible covalent alteration of specific chromatin domains, such as acetylation, methylation, phosphorylation, ADP-ribosylation and ubiquitination, which influence the accessibility of transcription complexes to distinct DNA elements, thus regulating gene expression. These modifications exert a fundamental role in the control of gene expression during embryogenesis and are involved in silencing specific genes in adult differentiated cells and tissues (1). Tumor cells have been shown to reactivate expression of these genes during their malignant conversion leading to uncontrolled proliferation (2). On the other hand, alteration of gene expression in cancer due to epigenetic modifications has also been correlated with downregulation of genes involved in cell cycle control and apoptosis (3-5).

Various covalent modifications which influence chromatin state are involved in regulating the expression of cancerrelated genes. In particular, enzymes that modulate chromatin structure through histone modifications are currently considered key regulators of tumorigenic events and can thus be considered as possible targets in cancer therapy (6). Histone modifications and DNA methylation maintain the equilibrium that regulates chromatin organization and function. Posttranscriptional modifications of histones play a fundamental role in regulating chromatin state and accessibility of transcription factors to the DNA and are, thus, considered to influence gene expression (7). The term 'histone code' is now widely used to describe complex patterns of $\mathrm{N}$-terminal histone modifications by phosphorylation, acetylation, methylation and possibly ubiquitination and their effects on the expression of individual genes $(8,9)$.

Balanced activities of histone acetyltransferases (HATs) and histone deacetylases (HDACs) determine the acetylation status of histones. HATs catalyse the addition of acetyl 
groups to lysine residues present in the histone tails, thereby neutralizing this portion of the histones and consequently loosening the nucleosome. Histone acetylation is, therefore, correlated with a relaxed chromatin state that favors accessibility of transcription factors to DNA elements. HDACs, on the other hand, remove acetyl groups from histone tails leading to packaging of chromatin into a condensed, repressed form, thus preventing the contact of transcription factors, regulatory complexes and RNA polymerases with the DNA with consequent silencing transcription (10). These effects are normally localized to specific portions of DNA since both HATs and HDACs can be associated with particular transcription factors or modulators that orientate the position of these enzymes in specific encoding regions and allow them to cooperate in transcriptional control (Fig. 1). As a consequence, only a small subset of encoding genes, estimated to be approximately $2-5 \%$, can be transcriptionally regulated by the histone acetylation state. Notably, such a limited percentage includes genes that exert a key role in cell cycle control and apoptosis (11). For this reason, modulating histone acetylation/deacetylation using specific inhibitors represents a novel and potential approach to cancer therapy. Intervening in modulating $\mathrm{HAT} / \mathrm{HDAC}$ activity with a therapeutic purpose is also supported by the evidence that HATs are often downregulated or mutated in certain tumors whereas HDACs are typically overexpressed in tumor cells $(12,13)$.

Histone deacetylase inhibitors (HDACIs) constitute a relatively new class of drugs with a high potential as anticancer agents. In vitro and in vivo evaluations have shown that these compounds have low toxicity for normal cells while selectively inducing apoptosis in several types of tumor cell lines $(14,15)$. A number of HDACIs are currently undergoing phase I and phase II clinical trials; some are in phase III or are already used in the therapy for hematological malignancies (16). In most cases, HDACI treatment induces a rapid accumulation of hyperacetylated histone proteins, thereby causing modifications in chromatin state and consequently affecting gene expression.

Recent expression profiling studies have confirmed that genes that exert a key role in cell fate can be modulated by HDACIs. One of the most characterized effects of different HDACIs in tumor cells is the induction of $\mathrm{p} 21^{\mathrm{WAF} 1 / \mathrm{CIP} 1}$, a cyclin-dependent kinase (cdk) inhibitor (17), together with downregulation of a number of other cell cycle regulatory genes $(18,19)$. Oligonucleotide microarray analyses to characterize the transcriptional profile after treatment with HDACIs in multiple myeloma cells have demonstrated early changes in gene expression of certain regulatory factors involved in apoptosis and cell survival as well as drug resistance, DNA repair, proteasome function and cell cycle regulation $(11,20)$.

However, HDACIs have been shown to induce growth arrest and apoptosis in a variety of human tumor cells by mechanisms that cannot only be attributed to histone hyperacetylation and consequent gene transcription modulation. Several non-histone proteins, which exert a role in controling apoptosis, including p53, Hsp90, NF- $\mathrm{kB}$ and tubulin, can also interact with HDACs and behave as their substrates, thus being stabilized in an acetylated form after treatment with HDACIs (21).
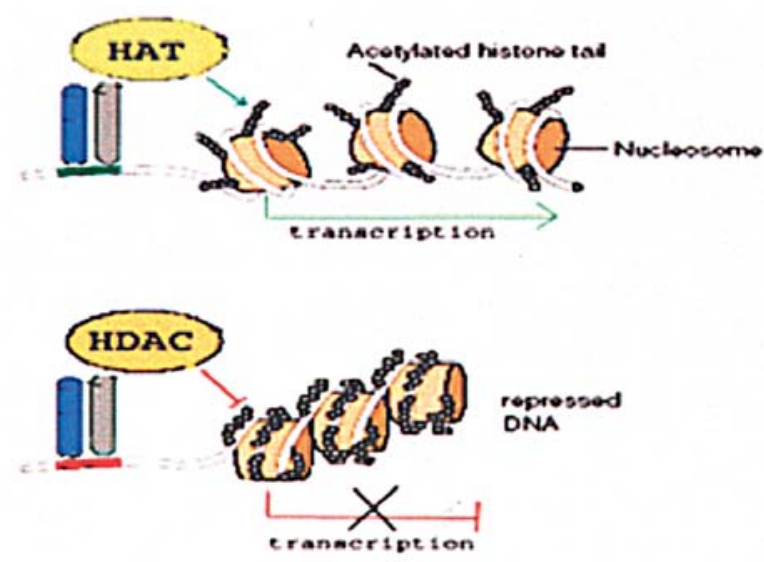

Figure 1. A simplified model of the influence of histone acetylation/ deacetylation on transcriptional activity.

Recent findings have highlighted a role of HDACIs in counteracting angiogenesis (22-24), tumor progression and invasiveness (25-27), thus, supporting the therapeutic potential of these drugs.

The synergistic activity of HDACIs in combination with chemotherapy/radiotherapy as well as biological therapeutic agents has been widely described (28-30).

This review summarizes the results of recently published data on the effects of HDACIs in different tumor models, with a special focus on the molecular mechanisms of antitumor activity and their clinical applications.

\section{The regulation of gene expression by histone modifications: HATs and HDACs}

Eukaryotic DNA is organized into nucleosomes, which consist of 146 base pairs of DNA wrapped around a core of eight histone proteins, 2(H2A, H2B, H3, H4). Nucleosome packages create higher-order structures to form condensed chromatin. The N-terminal tails of the histones play a fundamental role in the regulation of chromatin structures. Acetylation of the lysine residues in the histone tails abrogates their positive charge, resulting in the destabilization of the association of histone and the negatively charged phosphate backbone of DNA. Thus, histone acetylation can result in the unwinding of the nucleosomal array, thereby favoring gene expression, since acetylation increases accessibility of transcription factors to DNA. Both HAT and HDAC activities can be recruited to target genes in complexes with sequencespecific transcription factors and their cofactors (Fig. 1).

Nuclear receptors of the steroid or retinoid superfamily, such as retinoic acid receptors (RAR) or thyroid hormone receptors are associated, in the absence of ligands, with corepressors and HDACs forming a large complex, thereby inhibiting transcription (31-33). Upon ligand binding, the complex dissociates and the corepressors are replaced by coactivator proteins, such as SRC-1 or CBP, which exert HAT activity (34). The ligand-induced switch of nuclear receptors from repression to activation thus reflects the change in the complex of corepressor with coactivator proteins and HDAC with HAT activity. 


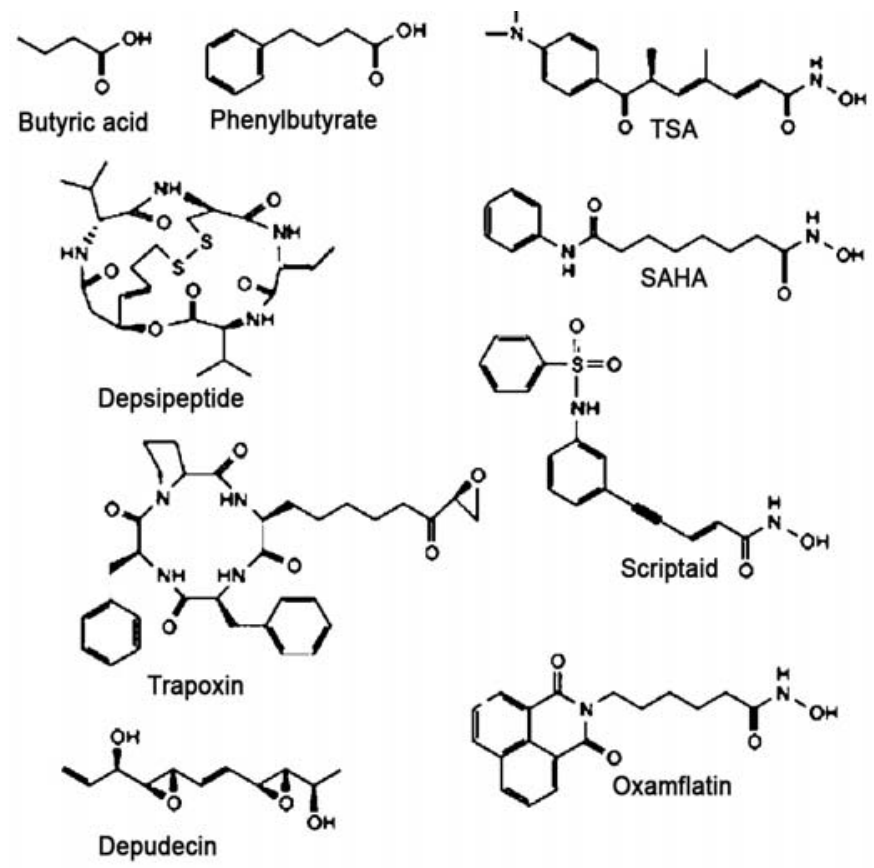

Figure 2. Chemical structure of selected histone deacetylase inhibitors.

Histone acetyltransferases (HAT) are enzymes that acetylate lysine residues present in the histone tails by transferring an acetyl group from acetyl CoA to lysine thereby forming $\varepsilon$-N-acetyl lysine (35). Mammalian HATs include two types, $\mathrm{A}$ and $\mathrm{B}$, which are characterized on the basis of their differing roles. Type A HATs play a key role in the regulation of gene expression since they behave as transcriptional coactivators. Type B HATs are mainly involved in the assembly of nascent histones into chromosomes.

\section{The most studied type A HATs}

$C B P / p 300$. CBP (CREB binding protein) and p300 are two closely related mammalian proteins that possess HAT activity (35) and are capable of acetylating all four core histones. Both proteins have been identified as coactivators of transcription and are known to interact with the histone acetyltransferase $\mathrm{P} / \mathrm{CAF}$ (36).

The gene encoding for CBP is known to be mutated in patients with Rubinstein-Taybi syndrome, a well-characterized developmental disorder, which is associated with an increased risk of cancer (37).

Mutations in p300 have been described in epithelial malignancies (38). In addition, epigenetic mechanisms, such as p300 promoter methylation, have been found as a silencing modality of this gene in tumor models contributing to tumor invasion and metastasis (39).

Gcn5-P/CAF. Gcn5 was originally identified as a gene required for amino acid biosynthesis in yeast. Subsequent studies revealed that Gcn5 is a subunit of both the ADA (40) and SAGA protein complexes $(41,42)$ and that it behaves like a transcriptional activator. P/CAF (p300/CBP associated factor) the human homolog of Gcn5 (43) was first identified as a protein that interacts with $\mathrm{CBP}$ protein. $\mathrm{P} / \mathrm{CAF}$ exhibits histone acetyltransferase activity since it can acetylate free $\mathrm{H} 3$ and $\mathrm{H} 4$ and nucleosomal H3 (44). P/CAF associates with many other nuclear proteins and is also reported to acetylate several transcription factors (45).

MYST/SAS/Tip60. This group includes Esa1 and Tip60 proteins (46). Esa1, which is an essential protein in yeast, and its homolog MOF protein in Drosophila have been shown to acetylate histones H4, H3 and H2A (47). Tip60 (Tat interacting protein 60) was originally identified as an acetyl transferase which interacts with HIV-1 transactivator protein Tat (48).

TAFII250. TAFII250, a component of the general transcription factor TFIID, can act as a transcriptional coactivator and can contribute to the regulation of promoter selectivity (49). It has been recently demonstrated that this protein possesses histone acetyltransferase activity (50).

Hat1. Hat 1 represents a type B HAT (51) which participates in the acetylation of newly synthesized histones during the process of chromatin assembly.

The activities of HDACs determine a hypoacetylated state of chromatin by removing acetyl groups from the histone tails. Mammalian HDACs can be divided into three subclasses.

Class I enzymes are homologous to the yeast Rpd3 protein and include HDAC1, 2, 3 and 8 with molecular masses ranging from 40 to $55 \mathrm{kDa}$. Their activities are usually localized in the nucleus and seem to be ubiquitously expressed in human tissues (10). Class II enzymes include HDAC4, 5, 6 and 7 which are larger proteins ( 120-130 kDa) related to the yeast Hda1 protein (22). Class II HDACs have been shown to localize either in the nucleus or cytoplasm thereby suggesting their involvement in deacetylation of nonhistone proteins.

According to sequence homology and modular arrangement, class II can be subdivided into IIa (HDAC4, 5, 7 and 9) and IIb (HDAC6 and 10). Both class I and II HDACs possess a highly conserved catalytic domain of approximately 390 amino acids and appear to deacetylate their substrates by activating a water molecule with a divalent zinc cation in cooperation with histidine-aspartate residues (21).

Recently, a third non-classic group of HDACs with homology to the yeast SIR2 (silent information regulator 2) protein has been discovered. This group of deacetylases, named 'sirtuins', operates by a very different mechanism that requires $\mathrm{NAD}^{+}$as a substrate and is insensitive to inhibition by compounds such as hydroxamic acid derivatives (52). The sirtuin family is conserved from archaeobacteria to eukaryotes (52). SIR2 has been shown to regulate lifespan in yeasts and Drosophila and seems to regulate longevity by participating in the caloric restriction pathway (53). In mammals, there are seven homologs of the yeast Sir2 gene, SIRT1-7, each with significant diversity in function. Mammalian sirtuins can be localized to the nucleus, cytoplasm or mitochondria, with distinct substrates and a broad range of functions (54).

Since HDACs are typically overexpressed in tumor cells (55-57), inhibition of HDACs can be a selective manner for inducing differentiation of tumor cells or specifically stimulating apoptosis. Therefore, inhibition of HDACs represents a promising approach for the treatment of various cancers.

Moreover, some of the genes encoding HDACs have been shown to be rearranged in the context of chromosomal translocations in human acute leukemias and solid tumors 
Table I. Several classes of HDAC inhibitors.

\begin{tabular}{|c|c|c|c|c|}
\hline \multirow[t]{2}{*}{ Class } & \multirow[t]{2}{*}{ Compound } & \multicolumn{3}{|c|}{ Activity } \\
\hline & & Cell culture & Animal models & Clinical trials \\
\hline \multirow[t]{5}{*}{ Short chain fatty acids } & Sodium butyrate & $*$ & $*$ & $*$ \\
\hline & Phenylbutyrate & $*$ & $*$ & $*$ \\
\hline & Phenylacetate & $*$ & $*$ & $*$ \\
\hline & Valproic acid & $*$ & $*$ & $*$ \\
\hline & Pivanex & $*$ & $*$ & $*$ \\
\hline \multirow[t]{11}{*}{ Hydroxamic acids } & Trichostatin A (TSA) & $*$ & $*$ & $*$ \\
\hline & Suberoylanilide hydroxamic acid (SAHA) & $*$ & $*$ & $*$ \\
\hline & M-carboxycinnamic acid (CBHA) & $*$ & $*$ & $*$ \\
\hline & Azelaic bis-hydroxamic acid (ABHA) & $*$ & $*$ & $*$ \\
\hline & LBH589 & $*$ & $*$ & $*$ \\
\hline & Scriptait & $*$ & $*$ & $*$ \\
\hline & Pyroxamide & $*$ & $*$ & $*$ \\
\hline & Oxamflatin & $*$ & & \\
\hline & PDX-101 & $*$ & & \\
\hline & LAQ-824 & $*$ & & \\
\hline & ITF 2357 & $*$ & $*$ & $*$ \\
\hline \multirow[t]{5}{*}{ Cyclic tetrapeptides } & Depsipeptide (FK228) & $*$ & $*$ & $*$ \\
\hline & Apicidine & $*$ & $*$ & \\
\hline & Trapoxin & $*$ & $*$ & \\
\hline & Depudesin & $*$ & & \\
\hline & CHAP & $*$ & & \\
\hline \multirow[t]{2}{*}{ Synthetic benzamides } & MS-275 & $*$ & $*$ & $*$ \\
\hline & CI-994 & $*$ & $*$ & $*$ \\
\hline \multirow[t]{2}{*}{ Ketones } & Trifluoromethyl ketone & $*$ & & \\
\hline & Ketomides & $*$ & & \\
\hline
\end{tabular}

(12). In addition, some HDACs are aberrantly recruited by proteins generated by rearranged chromosomal regions (58). Typical examples are PML-RARa, the protein of acute promyelocytic leukemia (APL), and AML1-ETO, the protein of acute myeloid leukemia (AML). They are two fusion proteins generated by translocations that aberrantly recruit HDACs to target genes leading to specific gene repression $(16,58)$.

AML1-ETO, for instance, blocks retinoic acid signaling in hematopoietic cells thereby inhibiting cell differentiation. Importantly, treatment of AML or APL leukemia with retinoic acid plus HDAC inhibitors has been shown to result in growth arrest and myeloid differentiation $(59,60)$.

\section{HDAC inhibitors: Potent and selective anticancer drugs}

There is ample evidence, both in vitro and in vivo, that HDACIs block the enzymatic activity of HDACs and induce hyperacetylation of histones.

Several classes of HDACIs have been widely described including i) short chain fatty acids, such as butyric and valproic acids; ii) hydroxamic acids, such as trichostatin A
(TSA), suberoylanilide hydroxamic acid (SAHA) and oxamflatin; iii) cyclic peptides, such as depsipeptide and trapoxin; and iv) benzamides such as CI-994 (Table I).

Originally, dimethyl sulphoxide was the first chemical of natural origin that was shown to induce histone hyperacetylation and cell differentiation (61). However, successively, owing to its toxicity, the attention was given to other agents.

Among the HDACIs of natural origin, sodium butyrate, a short chain fatty acid derived from the bacterial fermentation of fibers in the colon (62), and tricostatin A (TSA), a hydroxamic acid derivative isolated from Streptomyces (63), represent the most studied compounds. Sodium butyrate has been shown to induce cell cycle arrest and apoptosis in a wide variety of tumor cell types (64-66). However, butyrate displays a low clinical potential because of its instability when administered in vivo (67). Therefore, more stable butyrate analogs with a clinical potential, such as phenylbutyrate and tributyrine, have been developed and used as apoptotic inducers in many tumor models (68-70). TSA, although very effective as an HDACI and apoptotic inducer in tumor cells, has been shown to be unstable under in vivo conditions and to exert excessive toxicity (20). However, the apoptotic efficacy 
displayed by TSA in vitro has lead to the production of synthetic hydroxamic acid compounds with high clinical potential.

The hydroxamic acid class of HDACIs has attracted the attention of oncologists because of their remarkable and selective efficacy in cancer cells (71-74). Specifically, suberoylanilide hydroxamic acid (SAHA), which is already approved for patients with hematological malignancies (vorinostat, Zolinza ${ }^{\circledR}$ ), is currently of interest due to its capability of inducing apoptosis in a number of tumor cell types, whereas normal cells appear to be relatively resistant $(75,76)$. Clinical investigations have provided evidence that SAHA exhibits a high therapeutic potential for different forms of tumors at doses that are well tolerated by patients (77). In addition, SAHA seems to exert antitumor effects in a synergistic manner with various compounds such as anticancer drugs $(29,30)$, topoisomerase inhibitors $(29,78)$, proteasome inhibitors (79-82), TRAIL (83) and Imatinib (84). Other hydroxamic acids, including scriptaid (85), ITF 2357 $(15,86,87)$ and LBH589 $(88,89)$, currently have a high impact on clinical applications because of their relative low toxicity profile and selective antitumor activitiy.

Cyclic peptides include trapoxin A and B, depudecin and cyclic tetrapeptides such as apicidin and FK228, also known as depsipeptide. All of these compounds have been shown to inhibit cell proliferation in several human cancer cell lines at nanomolar ranges (75).

The benzamide class of HDACIs include two compounds, MS-275 (90) and CI-994 (91,92), which seem to have a high potential in the treatment of different types of tumors.

Considering that tumor cells are often characterized by a hypoacetylated state of chromatin associated with transcriptional repression of pro-apoptotic genes, the use of HDACIs can be considered as a general approach to specifically stimulate apoptosis in tumor cells.

\section{Molecular aspects of HDACI pleiotropic antitumor action}

The molecular mechanisms responsible for the selective susceptibility of cancer cells to the effects of HDACIs have not been completely elucidated. However, a number of relevant studies have been performed.

Many lines of evidence suggest that tumor cells are characterized by histone hypoacetylation and that overexpression of HDACs is involved in tumorigenesis of various human malignancies $(12,22)$. In accordance, it has been shown that histone hypoacetylation induces repression of tumor suppressor gene expression (93).

Treatment of tumor cells with HDACIs can be responsible for acetylation of histones, thus inducing derepression of gene expression leading to increased susceptibility of tumor cells to apoptosis $(20,55)$.

Other authors have proposed that the different behavior of HDACIs in tumor vs non-tumor cells is most likely correlated with differential expression of thioredoxin, a factor present in normal cells but poorly expressed in tumor cells, a condition that in normal cells could represent a defensive mechanism against oxidative stress and apoptosis induced by HDACIs $(94,95)$.
Studies on gene expression profiles induced by different HDACIs demonstrated that these drugs modulated a set of genes involved in several pathways regulating cell cycle and apoptosis (20).

A typical effect of HDACIs in many tumor cells is the induction of the tumor suppressor $\mathrm{p} 21^{\mathrm{WAF} 1 / \mathrm{CIP} 1}$, which plays a major role in growth arrest as well as in apoptosis (96). Increased p21 expression has been correlated with both p53dependent and -independent pathways (97). Moreover, it has been reported that HDACIs upregulate, apart from p21, other genes with antiproliferative functions including p16, p57 Kip2 and p19, while they downregulate several genes with proliferative functions, which are frequently overexpressed in tumor cells, including CDK4, CDC25; various cyclins, proliferating cell nuclear antigen (PCNA) and Ki-67 $(11,20,98)$. Finally, HDACIs have been also shown to induce upregulation of several pro-apoptotic genes, such as Apaf-1 and caspase-9, and downregulation of anti-apoptotic genes such as Bcl-2 and survivin (11).

A wide description of the apoptotic mechanism induced by SAHA was recently described in hepatocarcinoma cells in comparison with primary human hepatocytes (PHH) (79). In HCC cells SAHA has been shown to potently induce the extrinsic apoptotic pathway, increasing the expression of both FasR and FasL, caspase- 8 and t-Bid production, and contemporaneously the apoptotic intrinsic pathway by upregulating pro-apoptotic members of the Bcl-2 family, such as Bim isoforms and $\mathrm{Bcl}-\mathrm{Xs}$, which is an isoform derived by alternative splicing of the Bcl-X transcript. In HCC cells SAHA was also shown to synergistically interact with the proteasome inhibitor bortezomib with a complex pleiotropic mechanism. Notably, neither SAHA alone nor the combination SAHA/bortezomib has been shown to exert any effect in PHH (79).

Recently, it has been proposed that HDACI-induced chromatin remodeling cannot be the only mechanism responsible for the antiproliferative/pro-apoptotic action of these drugs. An increasing list of non-histone proteins, including p53, NF-кB, Hsp90, $\alpha$-tubulin p300 and FOXO-1, have been identified as HDAC substrates (21) thereby suggesting that acetylation can directly modulate effectors of apoptotic/cell survival mechanisms. Moreover, evidence has been provided that interaction of HDACIs with HDACs can modulate the formation or dissociation of protein complexes thus influencing key regulatory events determining cell fate. One significant example is given by the relationship between HDACs, the PP1 phosphatase and the pro-survival kinase Akt. Disruption of HDAC-PP1 complexes, induced by HDACIs, has been demonstrated to lead to an increased association of PP1 with phospho-Akt, resulting in Akt dephosphorylation and inactivation with consequent cell death (99).

Acetylation of p53 by HDACIs has been reported in several tumor systems (100) and has been correlated with p53 stabilization and cell cycle arrest and apoptosis (101). It has been recently suggested that acetylated p53 favors the production of nuclear complexes by recruiting HATs that are involved in mediating histone acetylation with the consequent activation of a set of pro-apoptotic genes (102).

HDACIs have also been shown to promote anti-angiogenic effects in different tumor cells $(103,104)$ and inhibit cell 
invasiveness (105). Evidence has also been provided that HDACIs are capable of downregulating metalloproteinases (MMPs) $(106,107)$.

Notably, several HDACIs seem to exert an antitumor effect in a synergistic manner with different anticancer compounds and to overcome the resistance induced by conventional chemotherapeutic drugs (79-83).

In this regard, evidence has indicated that HDACIs are capable of sensitizing tumor cells to TRAIL-mediated death signaling. It has been shown that many types of cancers fail to undergo apoptosis in response to TRAIL treatment due to overexpression of decoy receptors or anti-apoptotic components such as Flip or IAPs. Therefore, combination therapies of TRAIL and HDACIs can result in sensitization of tumor cells towards TRAIL-mediated death signaling. Several classes of HDACIs have been shown to synergize with exogenously added TRAIL to induce apoptosis in different tumor cell lines $(86,108)$.

In summary, several lines of evidence indicate that HDACIs exert complex and multiple mechanisms leading to inhibition of cell proliferation and induction of apoptosis in different tumor models. HDACIs seem to exert a selective efficacy in tumor cells and a remarkable tendency to synergistically act when administered together with chemotherapeutic drugs or apoptotic compounds with low toxicity.

\section{Clinical investigations and therapeutic impact}

A number of HDACIs which exhibit remarkable antitumor activity in vivo and low toxicity profiles are currently in clinical trials (Table I). Most of these drugs are in phase I and phase II evaluation for the treatment of hematological malignancies as well as solid tumors. HDACIs are administered either as monotherapy or in combination with other drugs. Some HDACIs are also used for other medical conditions including urea cycle disorder (109), sickle cell anemia (110-112) adrenoleukodystrophy (113), cystic fibrosis (114) and Fragile $\mathrm{X}$ syndrome (115). Valproic acid is well known in the field of neurology and widely used as an anti-epileptic (116).

The HDACIs in clinical trials against tumors include butyric acid derivatives (mostly sodium phenylbutyrate); valproic acid; hydroxamic acids such as SAHA, LAQ-824 and pyroxamide; benzamides including MS-275 and CI-994; and depsipeptide.

Short chain fatty acids, such as butyric acid derivatives and valproic acid, are very well tolerated in patients but show short plasma half-life due to rapid metabolism, thus requiring high doses for therapeutic effects (117). Among the butyric acid derivatives, sodium phenylbutyrate has been the most extensively investigated. As suggested by a phase I clinical study, intravenous or oral administration of phenylbutyrate, at concentrations that induce histone acetylation in vitro, is clinically well tolerated in patients with refractory solid tumors (118) or with AML (119).

Significantly, the use of phenylbutyrate or other HDACIs has been shown to sensitize leukemic blasts from AML patients to the differentiating effect of retinoic acid (21). Similarly, retinoic acid plus phenylbutyrate therapy has been reported to provide a good response in pro-myelocytic leukemia patients with PML-RARa fusion protein (120).
Valproic acid has been shown to induce differentiation of breast and colon carcinoma cells, as well as leukemic blasts from AML patients, and to cause reduction in tumor growth and metastasis formation in animal models (121). Clinical studies are ongoing and the preliminary results suggest a promising activity of valproic acid both in solid and hematopoietic malignancies $(122,123)$.

Among the compounds belonging to the hydroxamate class, SAHA (vorinostat, Zolinza ${ }^{\circledR}$ ) has been extensively considered, either alone or in combination with other drugs, for clinical studies in several neoplastic forms $(71,72,78-82$, $124,125)$ and is already approved for therapy in patients with follicular lymphomas $(126,127)$. SAHA has been shown to be well tolerated at doses that caused biological activity. Phase I studies of orally administered SAHA to patients with advanced cancer demonstrated that SAHA can be administered safely for prolonged periods of time (77). Currently, there are multiple phase II studies in patients with hematologic and solid tumor malignancies that will aid in ascertaining the most optimal dosing regimen.

Depsipeptide (FK-228, romidepsin), a bicyclic peptide isolated from Chromobacterium violaceum, showed significant antitumor properties and is undergoing phase I-II clinical studies in hematopoietic malignancies and solid tumors $(128,129)$.

CI-994 (N-acetyldinalin) is a novel oral compound with a wide spectrum of antitumor activity. In vivo studies of CI-994 exhibited activity in tumors normally refractory to conventional anticancer agents. Cytostatic in vivo activity of CI-994 has been demonstrated in several tumor models such as colon, osteosarcoma, prostate carcinoma, mammary carcinoma and pancreatic ductal adenocarcinoma $(93,130)$.

Further studies need to define the optimal dosing schedule and elucidate the biological effects of HDAC inhibition in patients.

\section{Future directions/conclusions}

Considering that a hypoacetylated state of chromatin is a condition that can favor neoplastic transformation, regulating chromatin structure and function by histone deacetylase inhibitors can be a potential targeted therapy. It has recently been shown that HDACIs exert pleiotropic effects on cancer cells. This might be due to both transcriptional activation of specific gene targets, primarily including those involved in growth arrest and apoptosis, and post-transcriptional modifications of key regulatory proteins that promote apoptotic commitment. It remains to be elucidated how these mechanisms are less significant or even absent in normal cells.

In addition, further studies are needed to determine the exact therapeutic window of HDACIs in clinical applications and to identify proper combinations with other antitumor drugs already used in therapy or undergoing clinical evaluations.

\section{References}

1. Reik W: Stability and flexibility of epigenetic gene regulation in mammalian development. Nature 447: 425-432, 2007.

2. Miremadi A, Oestergaard MZ, Pharoah PD and Caldas C: Cancer genetics of epigenetic genes. Hum Mol Genet 16 (Spec 1): R28-R49, 2007. 
3. Kurdistani SK: Histone modifications as markers of cancer prognosis: a cellular view. Br J Cancer 97: 1-5, 2007.

4. Palii SS and Robertson KD: Epigenetic control of tumor suppression. Crit Rev Eukaryot Gene Expr 17: 295-316, 2007.

5. Lettini AA, Guidoboni M, Fonsatti E, Anzalone L, Cortini E and Maio M: Epigenetic remodelling of DNA in cancer. Histol Histopathol 22: 1413-1424, 2007.

6. Santos-Rosa $\mathrm{H}$ and Caldas $\mathrm{C}$ : Chromatin modifier enzymes, the histone code and cancer. Eur J Cancer 41: 2381-2402, 2005.

7. Schneider-Stock R and Ocker M: Epigenetic therapy in cancer: molecular background and clinical development of histone deacetylase and DNA methyltransferase inhibitors. IDrugs 10: 557-561, 2007.

8. Jenuwein T and Allis CD: Translating the histone code. Science 293: 1074-1080, 2001.

9. Mello JA and Almouzni G: The ins and outs of nucleosome assembly. Curr Opin Genet Dev 11: 136-141, 2001.

10. Gray SG and Ekstrom TJ: The human histone deacetylase family. Exp Cell Res 262: 75-83, 2001.

11. Mitsiades CS, Mitsiades NS, McMullan CJ, Poulaki V, Shringarpure R, Hideshima T, Akiyama M, Chauhan D, Munshi N, Gu X, Bailey C, Joseph M, Libermann TA, Richon VM, Marks PA and Anderson KC: Transcriptional signature of histone deacetylase inhibition in multiple myeloma: biological and clinical implications. Proc Natl Acad Sci USA 101: 540-545, 2004.

12. Mahlknecht U and Hoelzer D: Histone acetylation modifiers in the pathogenesis of malignant disease. Mol Med 6: 623-644, 2000.

13. Bryan EJ, Jokubaitis VJ, Chamberlain NL Baxter SW, Dawson E, Choong DY and Campbell IG: Mutation analysis of EP300 in colon, breast and ovarian carcinomas. Int J Cancer 102: 137-141, 2002.

14. Marks PA, Richon VM and Rifkind RA: Histone deacetylase inhibitors: inducers of differentiation or apoptosis in transformed cells. J Natl Cancer Inst 92: 1210-1216, 2000.

15. Armeanu S, Pathil A, Venturelli S, Mascagni P, Weiss TS, Gottlicher M, Gregor M, Lauer UM and Bitzer, M: Apoptosis on hepatoma cells but not on primary hepatocytes by histone deacetylase inhibitors valproate and ITF2357. J Hepatol 42: 210-217, 2005.

16. Somech R, Izraeli S and J Simon A: Histone deacetylase inhibitors: a new tool to treat cancer. Cancer Treat Rev 30: 461-472, 2004

17. Richon VM, Sandhoff TW, Rifking RA and Marks PA: Histone deacetylase inhibitor selectively induces p21WAF1 expression and gene-associated histone acetylation. Proc Natl Acad Sci USA 97: 10004-10019, 2000.

18. Bi $\mathrm{G}$ and Jiang $\mathrm{G}$ : The molecular mechanism of HDAC inhibitors in anticancer effects. Cell Mol Immunol 3: 285-290, 2006.

19. Warrener R, Beamish H, Burgess A, Waterhouse NJ, Giles N, Fairlie DP and Gabrielli B: Tumor cell-specific cytotoxicity by targeting cell cycle checkpoints FASEB J 17: 1550-1552, 2003.

20. Peart MJ, Smyth GK, van Laar RK, Bowtell, DD, Richon VM, Marks PA, Holloway AJ and Johnstone RW: Identification and functional significance of genes regulated by structurally different histone deacetylase inhibitors. Proc Natl Acad Sci USA 102: 3697-3702, 2005

21. Lin H, Chen C, Shuan L, Weng J and Chen C: Targeting histone deacetylase in cancer therapy. Med Res Rev: 1-17, 2006.

22. Liu T, Kuljaca S, Tee A and Marshall GM: Histone deacetylase inhibitors: multifunctional anticancer agents. Cancer Treat Rev 32: $157-165,2006$

23. Yang QC, Zeng BF, Shi ZM, Dong Y, Jiang ZM, Huang J, Lv YM, Yang CX and Liu YW: Inhibition of hypoxia-induced angiogenesis by trichostatin A via suppression of HIF-1a activity in human osteosarcoma. J Exp Clin Cancer Res 25: 593-599, 2006.

24. Kim MS, Kwon HJ, Lee YM, Baek JH, Jang JE, Lee SW, Moon EJ, Kim HS, Lee SK, Chung HY, Kim CW and Kim KW: Histone deacetylases induce angiogenesis by negative regulation of tumor suppressor genes. Nat Med 7: 437-443, 2001.

25. Lin KT, Yeh SH, Chen DS, Chen PJ and Jou YS: Epigenetic activation of alpha4, beta2 and beta6 integrins involved in cell migration in trichostatin A-treated Hep3B cells. J Biomed Sci 12: $803-813,2005$.
26. Klisovic DD, Klisovic MI, Effron D, Liu S, Marcucci G and Katz SE: Depsipeptide inhibits migration of primary and metastatic uveal melanoma cell lines in vitro: a potential strategy for uveal melanoma. Melanoma Res 15: 147-153, 2005.

27. Whetstine JR, Ceron J, Ladd B, Dufourcq P, Reinke V and Shi Y: Regulation of tissue-specific and extracellular matrix-related genes by a class 1 histone deacetylase. Mol Cell 18: 483-490, 2005 .

28. Kim MS, Blake M, Baek JH, Kohlhagen G, Pommier Y and Carrier F: Inhibition of histone deacetylase increases cytotoxicity to anticancer drugs targeting DNA. Cancer Res 63: 7291-7300, 2003.

29. Ocker M, Alajati A, Ganslmayer M, Zopf S, Luders M, Neureiter D, Hahn EG, et al: The histone-deacetylase inhibitor SAHA potentiates proapoptotic effects of 5-fluorouracil and irinotecan in hepatoma cells. J Cancer Res Clin Oncol 131: 385-394, 2005.

30. Dey P: Chromatin remodeling, cancer and chemotherapy. Curr Med Chem 13: 2909-2919, 2006

31. Matsushita H, Scaglioni PP, Bhaumik M, Rego EM, Cai LF, Majid SM, Miyachi H, Kakizuka A, Miller WH Jr and Pandolfi PP: In vivo analysis of the role of aberrant histone deacetylase recruitment and RAR alpha blockade in the pathogenesis of acute promyelocytic leukemia J Exp Med 203: 821-828, 2006.

32. Jeyakumar M, Liu XF, Erdjument-Bromage H, Tempst P and Bagchi MK: Phosphorylation of thyroid hormone receptorassociated nuclear receptor corepressor holocomplex by the DNA-dependent protein kinase enhances its histone deacetylase activity. J Biol Chem 282: 9312-9322, 2007.

33. Ropero $\mathrm{S}$ and Esteller $\mathrm{M}$ : The role of histone deacetylases (HDACs) in human cancer. Mol Oncol 1: 19-25, 2007.

34. Ryan CM, Harries JC, Kindle KB, Collins HM and Heery DM Functional interaction of CREB binding protein (CBP) with nuclear transport proteins and modulation by HDAC inhibitors Cell Cycle 5: 2146-2152, 2006

35. Marmorstein R and Roth SY: Histone acetyltransferases: function, structure and catalysis. Curr Opin Genet Dev 11 : 155-161, 2001.

36. Chérasse Y, Maurin AC, Chaveroux C, Jousse C, Carraro V, Parry L, Deval C, Chambon C, Fafournoux P and Bruhat A: The p300/CBP-associated factor (PCAF) is a cofactor of ATF4 for amino acid-regulated transcription of CHOP. Nucleic Acids Res 35: 5954-5965, 2007.

37. Roelfsema JH and Peters DJ: Rubinstein-Taybi syndrome: clinical and molecular overview. Expert Rev Mol Med 20: 1-16, 2007.

38. Tillinghast GW, Partee J, Albert P, Kelley JM, Burtow KH and Kelly K: Analysis of genetic stability at the EP300 and CREBBP loci in a panel of cancer cell lines. Genes Chromosomes Cancer 37: 121-131, 2003.

39. Zhang C, Li K, Wei L, Li Z, Yu P, Teng L, Wu K and Zhu J: p300 expression repression by hypermethylation associated with tumour invasion and metastasis in oesophageal squamous cell carcinoma. J Clin Pathol 60: 1249-1253, 2007.

40. Horiuchi J, Silverman N, Marcus GA and Guarente L: ADA3, a putative transcriptional adaptor, consists of two separable domains and interacts with ADA2 and GCN5 in a trimeric complex. Mol Cell Biol 15: 1203-1209, 1995.

41. Baker SP and Grant PA: The SAGA continues: expanding the cellular role of a transcriptional co-activator complex. Oncogene 26: 5329-5340, 2007.

42. Nagy $Z$ and Tora L: Distinct GCN5/PCAF-containing complexes function as co-activators and are involved in transcription factor and global histone acetylation. Oncogene 26: 5341-5357, 2007

43. Candau R, Moore PA, Wang L, Barlev N, Ying CY, Rosen CA and Berger SL: Identification of human proteins functionally conserved with the yeast putative adaptors ADA2 and GCN5 Mol Cell Biol 16: 593-602, 1996.

44. Dilworth FJ, Seaver KJ, Fishburn AL, Htet SL and Tapscott SJ: In vitro transcription system delineates the distinct roles of the coactivators pCAF and p300 during MyoD/E47-dependent transactivation. Proc Natl Acad Sci USA 101: 11593-11598, 2004.

45. Marmorstein R: Structure of histone acetyltransferases. J Mol Biol 311: 433-444, 2001.

46. Clarke AS, Samal E and Pillus L: Distinct roles for the essential MYST family HAT Esalp in transcriptional silencing. Mol Biol Cell 17: 1744-1757, 2006. 
47. Clarke AS, Lowell JE, Jacobson SJ and Pillus L: Esa1p is an essential histone acetyltransferase required for cell cycle progression 1. Mol Cell Biol 19: 2515-2526, 1999.

48. Kamine J, Elangovan B, Subramanian T, Coleman D and Chinnadurai G: Identification of a cellular protein that specifically interacts with the essential cysteine region of the HIV-1 Tat transactivator. Virology 216: 357-366, 1996.

49. Jacobson RH, Ladurner AG, King DS and Tjian R: Structure and function of a human TAFII 250 double bromodomain module. Science 288: 1422-1425, 2000.

50. Gegonne A, Weissman JD and Singer DS: TAFII55 binding to TAFII250 inhibits its acetyltransferase activity. Proc Natl Acad Sci USA 98: 12432-12437, 2001.

51. Parthun MR: Hat1: the emerging cellular roles of a type B histone acetyltransferase. Oncogene 26: 5319-5328, 2007.

52. Yang T, Fu M, Pestell R and Sauve AA: SIRT1 and endocrine signaling. Trends Endocrinol Metab 17: 186-191, 2006.

53. Defossez P, Lin S and McNabb DS: Sound silencing: the Sir2 protein and cellular senescence. Bioessays 23: 327-332, 2001.

54. Whittle JR, Powell MJ, Popov VM, Shirley LA, Wang C and Pestell RG: Sirtuins, nuclear hormone receptor acetylation and transcriptional regulation. Trends Endocrinol Metab 18: 356-364, 2007.

55. Marks PA, Richon VM and Rifkind RA: Histone deacetylases and cancer: causes and therapies. Nat Rev Cancer 1: 194-202, 2001.

56. Wang C, Fu M, Mani S, Wadler S, Senderowicz AM and Pestell RG: Histone acetylation and the cell cycle in cancer. Front Biosci 6: D610-D629, 2001.

57. Conley BA, Wright JJ and Kummar S: Targeting epigenetic abnormalities with histone deacetylase inhibitors. Cancer 15: 832-840, 2006.

58. Amann JM, Nip J, Strom DK, et al: ETO, a target of $\mathrm{t}(8 ; 21)$ in acute leukaemia, makes distinct contacts with multiple histone deacetylases and binds $\mathrm{mSin} 3$ through its oligodimerization domain. Mol Cell Biol 21: 6470-6483, 2001.

59. Ferrara FF, Fazi F, Bianchini A, Padula F, Gelmetti V, Minucci S, Mancini M, Pelicci PG, Lo Coco F and Nervi C: Histone deacetylase-targeted treatment restores retinoic acid signaling and differentiation in acute myeloid leukemia. Cancer Res 61: $2-7,2001$

60. Cimino G, Lo-Coco F, Fenu S, Travaglini L, Finolezzi E, Mancini M, Nanni M, Careddu A, Fazi F, Padula F, Fiorini R, Spiriti MA, Petti MC, Venditti A, Amadori S, Mandelli F, Pelicci PG and Nervi C: Sequential valproic acid/all-trans retinoic acid treatment reprograms differentiation in refractory and highrisk acute myeloid leukemia. Cancer Res 66: 8903-8911, 2006.

61. Marks PA and Breslow R: Dimethyl sulfoxide to vorinostat: development of this histone deacetylase inhibitor as an anticancer drug. Nat Biotechnol 25: 84-90, 2007.

62. Roy CC, Kien CL, Bouthillier L and Levy E: Short-chain fatty acids: ready for prime time? Nutr Clin Pract 21: 351-366, 2006.

63. Yoshida M, Matsuyama A, Komatsu Y and Nishino N: From discovery to the coming generation of histone deacetylase inhibitors. Curr Med Chem 10: 2351-2358, 2003.

64. Emanuele S, D'Anneo A, Bellavia G, Vassallo B, Lauricella M, De Blasio A, Vento R and Tesoriere G: Sodium butyrate induces apoptosis in human hepatoma cells by a mitochondria/ caspase pathway, associated with degradation of beta-catenin, pRb and Bcl-XL. Eur J Cancer 40: 1441-1452, 2004.

65. Archer SY, Meng S, Shei A and Hodin RA: p21WAF1 is required for butyrate mediated growth inhibition of human colon cancer cells. Proc Natl Acad Sci USA 95: 6791-6796, 1998.

66. Demary K, Wong L and Spanjaard RA: Effects of retinoic acid and sodium butyrate on gene expression, histone acetylation and inhibition of proliferation of melanoma cells. Cancer Lett 163: 103-107, 2001 .

67. Melchior SW, Brown LG, Figg WD, Quinn JE, Santucci RA, Brunner J, Thüroff JW, Lange PH and Vessella RL: Effects of phenylbutyrate on proliferation and apoptosis in human cancer cells in vitro and in vivo. Int J Oncol 14: 501-508, 1999.

68. Svechnikova I, Gray SG, Kundrotiene J, Ponthan F, Kogner P and Ekström TJ: Apoptosis and tumor remission in liver tumor xenografts by 4-phenylbutyrate. Int J Oncol 22: 579-588, 2003.

69. Su J, He L, Zhang N and Ho PC: Evaluation of tributyrin lipid emulsion with affinity to low-density lipoprotein: pharmacokinetics in adult male Wistar rats and cellular activity on Caco-2 and HepG2 cell lines. J Pharmacol Exp Ther 316: 62-70, 2006.
70. Kuefer R, Hofer MD, Altug V, Zorn C, Genze F, Kunzi-Rapp K, Hautmann RE and Gschwend JE: Sodium butyrate and tributyrin induce in vivo growth inhibition and apoptosis in human prostate cancer. Br J Cancer 26: 535-541, 2004.

71. Marks P: Discovery and development of SAHA as an anticancer agent. Oncogene 26: 1351-1356, 2007.

72. Grant S, Easley C and Kirkpatrick P: Vorinostat. Nat Rev Drug Discov 6: 21-22, 2007.

73. Kelly WK and Marks PA: Drug insight: histone deacetylase inhibitors - development of the new targeted anticancer agent suberoylanilide hydroxamic acid. Nat Clin Pract Oncol 3: 150-157, 2005.

74. Richon VM: Cancer biology: mechanism of antitumour action of vorinostat (suberoylanilide hydroxamic acid), a novel histone deacetylase inhibitor. Br J Cancer 95 (Suppl 1): 2-6, 2006.

75. Marks PA and Dokmanovic M: Histone deacetylase inhibitors: discovery and development as anticancer agents. Expert Opin Investig Drugs 14: 1497-1511, 2005.

76. Garber K: HDAC inhibitors overcome first hurdle. Nat Biotechnol 25: 17-19: 2007.

77. Kelly WK, O'Connor OA, Krug LM, Chiao JH, Heaney M, Curley T, MacGregore-Cortelli B, Tong W, Secrist JP, Schwartz L, Richardson S, Chu E, Olgac S, Marks PA, Scher H and Richon VM: Phase I study of an oral histone deacetylase inhibitor, suberoylanilide hydroxamic acid, in patients with advanced cancer. J Clin Oncol 10: 3923-3931, 2005.

78. Marchion DC, Bicaku E, Daud AI, Richon V, Sullivan DM and Munster PN: Sequence-specific potentiation of topoisomerase II inhibitors by the histone deacetylase inhibitor suberoylanilide hydroxamic acid. J Cell Biochem 15: 223-237, 2004.

79. Emanuele S, Lauricella M, Carlisi D, Vassallo B, D'Anneo A, Di Fazio P, Vento R and Tesoriere G: SAHA induces apoptosis in hepatoma cells and synergistically interacts with the proteasome inhibitor Bortezomib. Apoptosis 12: 1327-1338, 2007.

80. Pei XY, Dai Y and Grant S. Synergistic induction of oxidative injury and apoptosis in human multiple myeloma cells by the proteasome inhibitor bortezomib and histone deacetylase inhibitors. Clin Cancer Res 10: 3839-3852, 2004.

81. Yu C, Rahmani M, Conrad D, Subler M, Dent P and Grant S: The proteasome inhibitor bortezomib interacts synergistically with histone deacetylase inhibitors to induce apoptosis in $\mathrm{Bcr} / \mathrm{Abl}^{+}$cells sensitive and resistant to STI571. Blood 102: 3765-3774, 2003.

82. Drexler HC and Euler M: Synergistic apoptosis induction by proteasome and histone deacetylase inhibitors is dependent on protein synthesis. Apoptosis 10: 743-758, 2005.

83. Fandy TE, Shankar S, Ross DD, Sausville E and Srivastava RK: Interactive effects of HDAC inhibitors and TRAIL on apoptosis are associated with changes in mitochondrial functions and expressions of cell cycle regulatory genes in multiple myeloma. Neoplasia 7: 646-657, 2005.

84. Nimmanapalli R, Fuino L, Sobaugh C, RichonV and Balla K: Cotreatment with the histone dacetylase inhibitor suberoylanilide hydroxamic acid (SAHA) enhances imatinib-induced apoptosis of Bcr-Abl positive human acute leukaemia cells. Blood 101: 8236-8239, 2003.

85. Takai N, Ueda T, Nishida M, Nasu K and Narahara H: A novel histone deacetylase inhibitor, Scriptaid, induces growth inhibition, cell cycle arrest and apoptosis in human endometrial cancer and ovarian cancer cells. Int J Mol Med 17: 323-329, 2006.

86. Pathil A, Armeanu S, Venturelli S, Mascagni P, Weiss TS, Gregor M, Lauer UM and Bitzer M: HDAC inhibitor treatment of hepatoma cells induces both TRAIL-independent apoptosis and restoration of sensitivity to TRAIL. Hepatology 43: 425-434, 2006.

87. Leoni F, Fossati G, Lewis EC, Lee JK, Porro G, Pagani P, Modena D, Moras ML, Pozzi P, Reznikov LL, Siegmund B, Fantuzzi G, Dinarello CA and Mascagni P: The histone deacetylase inhibitor ITF2357 reduces production of proinflammatory cytokines in vitro and systemic inflammation in vivo. Mol Med 11: 1-15, 2005.

88. Giles F, Fischer T, Cortes J, Garcia-Manero G, Beck J, Ravandi F, Masson E, Rae P, Laird G, Sharma S, Kantarjian H, Dugan M, Albitar M and Bhalla K: A phase I study of intravenous LBH589, a novel cinnamic hydroxamic acid analogue histone deacetylase inhibitor, in patients with refractory hematologic malignancies. Clin Cancer Res 12: 4628-4635, 2006. 
89. Maiso P, Carvajal-Vergara X, Ocio EM, López-Pérez R, Mateo G, Gutiérrez N, Atadja P, Pandiella A and San Miguel JF: The histone deacetylase inhibitor LBH589 is a potent antimyeloma agent that overcomes drug resistance. Cancer Res 66: 5781-5789, 2006.

90. Saito A, Yamashita T, Mariko Y, Nosaka Y, Tsuchiya K, Ando T, Suzuki T, Tsuruo T and Nakanishi O: A synthetic inhibitor of histone deacetylase, MS-275, with marked in vivo antitumor activity against human tumors. Proc Natl Acad Sci USA 96: 4592-4597, 1999.

91. Nemunaitis JJ, Orr D, Eager R, Cunningham CC, Williams A, Mennel R, Grove W and Olson S: Phase I study of oral CI-994 in combination with gemcitabine in treatment of patients with advanced cancer. Cancer J 9: 58-66, 2003.

92. Prakash S, Foster BJ, Meyer M, Wozniak A, Heilbrun LK, Flaherty L, Zalupski M, Radulovic L, Valdivieso $M$ and LoRusso PM: Chronic oral administration of CI-994: a phase 1 study. Invest New Drugs 19: 1-11, 2001.

93. Minucci S and Pelicci PG: Histone deacetylase inhibitors and the promise of epigenetic (and more) treatments for cancer. Nat Rev Cancer 6: 38-51,2006.

94. Butler LM, Zhou X, Xu WS, Scher HI, Rifkind RA, Marks PA and Richon VM: The histone deacetylase inhibitor SAHA arrests cancer cell growth, upregulates thioredoxin: Proc Natl Acad Sci USA 99: 11700-11705, 2002.

95. Xu W, Ngo L, Perez G, Dokmanovic M and Marks PA: Intrinsic apoptotic and thioredoxin pathways in human prostate cancer cell response to histone deacetylase inhibitor. Proc Natl Acad Sci USA 103: 15540-15545, 2006.

96. Burgess AJ, Pavey S, Warrener R, Hunte, LJ, Piva TJ, Musgrove EA, Saunders N, Parsons PG and Gabrielli BG: Upregulation of p21WAF1/CIP1 by histone deacetylase inhibitors reduces their cytotoxicity. Mol Pharmacol 60: 828-837, 2001.

97. Archer SY, Johnson J, Kim HJ, Ma Q, Mou H, Daesety V, Meng S and Hodin RA: The histone deacetylase inhibitor butyrate downregulates cyclin B1 gene expression via a p21/WAF-1-dependent mechanism in human colon cancer cells. Am J Physiol Gastrointest Liver Physiol 289: 696-703, 2005.

98. Yokota T, Matsuzaki Y and Sakai T: Trichostatin A activates p18INK4c gene: differential activation and cooperation with p19INK4d gene. FEBS Lett 574: 171-175, 2004.

99. Chen CS, Weng SC, Tseng PH, Lin HP and Chen CS: Histone acetylation-independent effect of histone deacetylase inhibitors on Akt through the reshuffling of protein phosphatase 1 complexes. J Biol Chem 280: 38879-38887, 2005.

100. Roy S, Packman K, Jeffrey R and Tenniswood M: Histone acetylase inhibitors differentially stabilize p53 and induce cell cycle arrest or apoptosis in prostate cancer cells. Cell Death Differ 12: 482-491, 2005.

101.Luo J, Su F, Chen D, Shiloh A and Gu W: Deacetylation of p53 modulates its effects on cell growth and apoptosis. Nature 408: $377-381,2000$

102. Carlisi D, Vassallo B, Lauricella M, Emanuele S, D'Anneo A, Di Leonardo E, Di Fazio P, Vento R and Tesoriere G: Histone deacetylase inhibitors induce in human hepatoma HepG2 cells acetylation of p53 and histones in correlation with apoptotic effects. Int J Oncol 32: 177-184, 2008.

103. Kwon HJ, Kim MS, Kim MJ, Nakajima H and Kim KW: Histone deacetylase inhibitor FK228 inhibits tumor angiogenesis. Int J Cancer 97: 290-296, 2002.

104. Johnstone RW and Licht JD: Histone deacetylase inhibitors in cancer therapy: Is transcription the primary target? Cancer Cell 4: 13-18, 2003

105. Takada Y, Gillenwater A, Ichikawa $\mathrm{H}$ and Aggarwal BB: Suberoylanilide hydroxamic acid potentiates apoptosis, inhibits invasion, and abolishes osteoclastogenesis by suppressing nuclear factor-kappaB activation. J Biol Chem 281: 5612-5622, 2006.

106. Young DA, Lakey RL, Pennington CJ, Jones D, Kevorkian L, Edwards DR, Cawston TE and Clark IM: Histone deacetylase inhibitors modulate metalloproteinase gene expression in chondrocytes and block cartilage resorption. Arthritis Res Ther 7: R503-R512, 2005.

107. Vinodhkumar R, Song YS, Ravikumar V, Ramakrishnan G and Devaki T: Depsipeptide a histone deacetlyase inhibitor down regulates levels of matrix metalloproteinases 2 and 9 mRNA and protein expressions in lung cancer cells (A549). Chem Biol Interact 20: 220-229, 2007.
108. Reddy RM, Yeow WS, Chua A, Nguyen DM, Baras A, Ziauddin MF, Shamimi-Noori SM, Maxhimer JB, Schrump DS and Nguyen DM: Rapid and profound potentiation of Apo2L/ TRAIL-mediated cytotoxicity and apoptosis in thoracic cancer cells by the histone deacetylase inhibitor trichostatin A: the essential role of the mitochondria-mediated caspase activation cascade. Apoptosis 12: 55-71, 2007.

109. Brusilow SW, Danney M, Waber LJ, Batshaw M, Burton B, Levitsky L, Roth K, McKeethren C and Ward J: Treatment of episodic hyperammonemia in children with inborn errors of urea synthesis. N Engl J Med 310: 1630-1634, 1984.

110. Perrine SP, Ginder GD, Faller DV, Dover GH, Ikuta T, Witkowska HE, Cai SP, Vichinsky EP and Olivieri NF: A short-term trial of butyrate to stimulate fetal-globin-disorders. N Engl J Med 328, 81-86, 1993.

111. Dover GJ, Brusilow S and Charache S: Induction of fetal hemoglobin production in subjects with sickle cell anemia by oral sodium phenylbutyrate. Blood 84: 339-343, 1994.

112. Collins AF, Pearson HA, Giardina P, McDonagh KT, Brusilow SW and Dover GJ: Oral sodium phenylbutyrate therapy in homozygous beta thalassemia: a clinical trial. Blood 85: 43-49, 1995.

113.Kemp S, Wei HM, Lu JF, Braiterman LT, McGuinness MC, Moser AB, Watkins PA and Smith KD: Gene redundancy and pharmacological gene therapy: implication for X-linked adrenoleukodystrophy. Nat Med 4: 1261-1268, 1998.

114. Rubenstein RC and Zeitlin PL: A pilot clinical trial of oral sodium 4-phenylbutyrate (Buphenyl) in F508-homozygote cystic fibrosis patients. Am J Respir Crit Care Med 157: 484-490, 1998.

115. Chiurazzi P, Pomponi MG, Pietrobono R, Bakker CE, Neri G and Oostra BA: Synergistic effect of histone hyperacetylation and DNA demethylation in the reactivation of the FMRI gene. Hum Mol Genet 12: 2317-2323, 1999.

116. Van Breemen MS, Wilms EB and Vecht CJ: Epilepsy in patients with brain tumours: epidemiology, mechanisms, and management. Lancet Neurol 6: 421-430, 2007.

117. Gore SD and Carducci MA: Modifying histones to tame cancer: clinical development of sodium phenylbutyrate and other histone deacetylase inhibitors. Expert Opin Investig Drugs 9: 2923-2934, 2000.

118. Carducci MA, Gilbert J, Bowling MK, Noe D, Eisenberger MA, Sinibaldi V, Zabelina Y, Chen TL, Grochow LB and Donehower RC: A phase I clinical and pharmacological evaluation of sodium phenylbutyrate on an 120-h infusion schedule. Clin Cancer Res 7: 3047-3055, 2001.

119. Gore SD, Weng LJ, Zhai S, Figg WD, Donehower RC, Dover GJ, Grever M, Griffin CA, Grochow LB, Rowinsky EK, Zabalena Y, Hawkins AL, Burks K and Miller CB: Impact of the putative differentiating agent sodium phenylbutyrate on myelodysplastic syndromes and acute myeloid leukaemia. Clin Cancer Res 7: 2330-2339, 2001.

120.Zhou DC, Kim SH, Ding W, Schultz C, Warrell RP Jr and Gallagher RE: Frequent mutations in the ligand-binding domain of PML-RAR alpha after multiple relapses of acute promyelocytic leukemia: analysis for functional relationship to response to all-trans retinoic acid and histone deacetylase inhibitors in vitro and in vivo. Blood 99: 1356-1363, 2002.

121.Zhu P, Krämer $\mathrm{OH}$, Schimpf A, Giavara S, Sleeman JP, Lo Coco F, Nervi C, Pelicci PG and Heinzel T: Valproic acid defines a novel class of HDAC inhibitors inducing differentiation of transformed cells. EMBO J 20: 6969-6978, 2001.

122. Atmaca A, Al-Batran SE, Maurer A, Neumann A, Heinzel T, Hentsch B, Schwarz SE, Hövelmann S, Göttlicher M, Knuth A and Jäger E: Valproic acid (VPA) in patients with refractory advanced cancer: a dose escalating phase I clinical trial. Br J Cancer 97: 177-182, 2007.

123. Blaheta RA, Michaelis M, Driever PH and Cinatl J Jr: Evolving anticancer drug valproic acid: insights into the mechanism and clinical studies. Med Res Rev 25: 383-397, 2005.

124. Shen J, Huang C, Jiang L, Gao F, Wang Z, Zhang Y, Bai J, Zhou H and Chen Q: Enhancement of cisplatin induced apoptosis by suberoylanilide hydroxamic acid in human oral squamous cell carcinoma cell lines. Biochem Pharmacol 73: 1901-1909, 2007.

125. Rikiishi H, Shinohara F, Sato T, et al: Chemosensitization of oral squamous cell carcinoma cells to cisplatin by histone deacetylase inhibitor, suberoylanilide hydroxamic acid. Int J Oncol 30: 1181-1188, 2007. 
126.Lindemann RK, Newbold A, Whitecross KF, Cluse LA, Frew AJ, Ellis L, Williams S, Wiegmans AP, Dear AE, Scott CL, Pellegrini M, Wei A, Richon VM, Marks PA, Lowe SW, Smyth MJ and Johnstone RW: Analysis of the apoptotic and therapeutic activities of histone deacetylase inhibitors by using a mouse model of B cell lymphoma. Proc Natl Acad Sci USA 104: 8071-8076, 2007.

127. Mann BS, Johnson JR, He K, Sridhara R, Abraham S, Booth BP, Verbois L, Morse DE, Jee JM, Pope S, Harapanhalli RS, Dagher R, Farrell A, Justice R and Pazdur R: Vorinostat for treatment of cutaneous manifestations of advanced primary cutaneous T-cell lymphoma. Clin Cancer Res 13: 2318-2322, 2007.
128.Lech-Maranda E, Robak E, Korycka A and Robak T: Depsipeptide (FK228) as a novel histone deacetylase inhibitor: mechanism of action and anticancer activity. Mini Rev Med Chem 7: 1062-1069, 2007.

129. Marshall JL, Rizvi N, Kauh J, Dahut W, Figuera M, Kang MH, Figg WD, Wainer I, Chaissang C, Li MZ and Hawkins MJ: A phase I trial of depsipeptide (FR901228) in patients with advanced cancer. J Exp Ther Oncol 2: 325-332, 2002.

130.Lo Russo PM, Demchik L, Foster B, et al: Preclinical antitumor activity of CI-994. Invest New Drug 14: 349-356, 1996. 